\title{
Термомеханический анализ эффекта памяти формы полиуретанового композита, используемого для создания развертываемых конструкций космического назначения
}

\author{
(C) Т.А. Шалыгина ${ }^{1,2}$, С.Ю. Воронина ${ }^{1,2}$, А.Ю. Власов ${ }^{1}$, К.А. Пасечник ${ }^{1,2}$, И.В. Обверткин ${ }^{1,2}$ \\ ${ }^{1}$ Сибирский государственный университет науки и технологий им. акад. М.Ф. Решетнёва, \\ Красноярск, Россия \\ ${ }^{2}$ Федеральный исследовательский центр „Красноярский научный центр СО РАН“, \\ Красноярск, Россия \\ E-mail: leonova.ta@inbox.ru
}

Поступило в Редакцию 28 января 2019г.

В окончательной редакции 12 февраля 2019 г.

Принято к публикации 12 февраля 2019г.

\begin{abstract}
Исследована возможность применимости трехточечного изгибающего зажима термомеханического анализатора для исследования эффекта памяти формы у конструкционного полиуретанового композита. Изучены вязкоупругие свойства образца в области перехода из стеклообразного в высокоэластическое состояние. Определены параметры, влияющие на коэффициент восстановления исходной формы $\left(R_{r}\right)$ и коэффициент фиксации временной формы $\left(R_{f}\right)$. Установлены условия деформирования и охлаждения полиуретанового композита, позволяющие достичь значений $R_{r}=99.98 \%$ и $R_{f}=99.70 \%$.
\end{abstract}

DOI: 10.21883/PJTF.2019.09.47711.17713

Некоторые задачи космических технологий подразумевают использование крупногабаритных конструкций специального назначения (антенны современной спутниковой связи, солнцезащитные пространственные структуры, системы солнечных батарей и др.). Доставка на околоземную орбиту объектов таких размеров порождает множество задач, решение которых затрагивает различные области науки. В связи с этим активно исследуются новые материалы, обладающие эффектом памяти формы (ЭПФ), для изготовления трансформируемых конструкций с возможностью придания им временной компактной формы на Земле и восстановления развернутой (исходной) формы в космическом пространстве [1]. Применение полимерных материалов (ПМ) в этом случае обусловлено низкой стоимостью и снижением веса конструкций, подходящим температурным интервалом реализации и низкой температурой инициации ЭПФ (около $100^{\circ} \mathrm{C}$ ) [2]. ПМ, обладающим перечисленными выше достоинствами и используемым в качестве связующего при создании полимерных композиционных материалов, является реактопластичный полиуретан с ЭПФ [3].

Для моделирования рабочего процесса развертывания трансформируемых конструкций необходимо исследовать физические принципы алгоритма свободного восстановления замороженной деформации используемого материала с ЭПФ. Поэтому в настоящей работе приводятся результаты исследования ЭПФ у конструкционного полиуретанового композита (КПК), используемого для изготовления составных частей (шпангоутов) крупногабаритных трансформируемых рефлекторов космических антенн [4]. Целью работы является изучение воз- можной применимости трехточечного изгибающего зажима в режиме одноосной контролируемой изгибающей нагрузки термомеханического анализатора (ТМА) для исследования ЭПФ у КПК в условиях, приближенных к реальным. Кроме того, в данном исследовании особое внимание уделялось определению наиболее подходящего режима деформирования с точки зрения эффективной фиксации (упаковки) временной формы и точности восстановления (развертывания) исходной формы КПК.

Объектом исследования служит образец КПК, состоящий из полиуретановой матрицы Diaplex MP5510 (Япония) с температурой стеклования $T_{g}=55^{\circ} \mathrm{C}[5]$ и углеткани Ст 12073 (Россия). Образец был изготовлен методом контактного формования в Ресурсном центре коллективного пользования „Космические аппараты и системы“ ФБГОУ ВО „Сибирский государственный университет науки и технологий им. акад. М.Ф. Решетнёва“.

Термомеханические (ТМ) исследования вязкоупругих свойств КПК с ЭПФ были проведены с использованием динамического механического анализатора (ДМА) Q800 производства ТА Instruments (США). Измерение комплексного модуля Юнга $\left(E^{*}\right)$ образца осуществлялось с использованием трехточечного изгибающего зажима и линейного температурного сканирования в режиме нагревания от 0 до $100^{\circ} \mathrm{C}$ со скоростью $5^{\circ} \mathrm{C} / \mathrm{min}$. Частота динамического нагружения композита составила $1 \mathrm{~Hz}$, относительная деформация не более $0.1 \%$. Образец КПК представлял собой пластину размером $30 \times 12.5 \times 0.65 \mathrm{~mm}$. По значению точки перегиба температурной зависимости модуля упругости $E^{\prime}(T)$ в области перехода стеклования определялось значение $T_{g}$ согласно ГОСТ Р 56753-2015 (ИСО 6721-11:2012). 


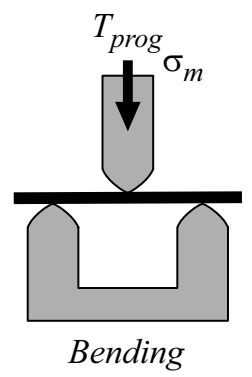

(1)

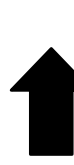

(4)

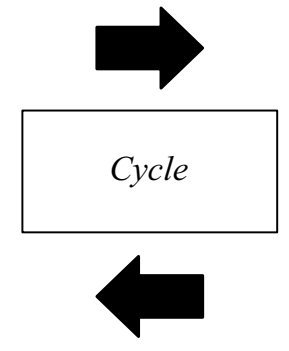

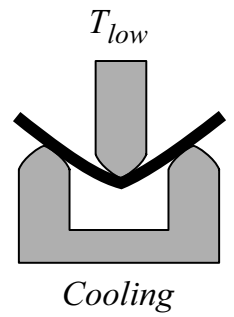

(2)

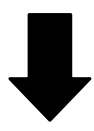

(3)

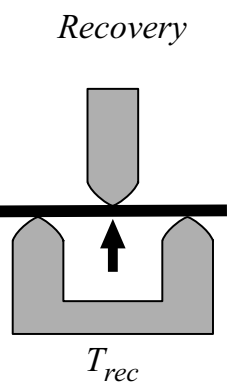

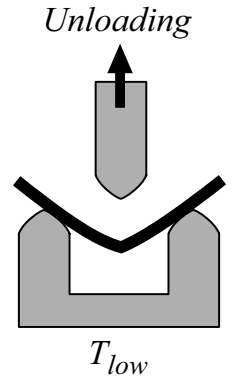

Рис. 1. Схематическое представление циклического термомеханического исследования эффекта памяти формы у конструкционного полиуретанового композита с использованием трехточечного изгибающего зажима.

Исследование ТМ-цикла ЭПФ КПК проводилось с использованием трехточечного изгибающего зажима термомеханического анализатора TMAQ400EM производства TA Instruments (США). Измерения выполнялись в режиме регулируемой изгибающей нагрузки и изменяющейся температуры по заданной программе с одновременным измерением продольного перемещения образца. Образец КПК представлял собой брусок размером $10 \times 1.22 \times 0.72 \mathrm{~mm}$.

Метод циклического ТМ-исследования ЭПФ, описанный в 1992 г. в работе [6], подразумевал наличие четырех этапов, включающих в себя: этап 1 - нагревание образца до температуры $T_{\text {prog }}$ (programming temperature), при которой осуществлялась деформация образца; этап $2-$ создание „замороженного“ деформированного состояния в процессе охлаждения до температуры ниже интервала стеклования $T_{\text {low }}$ (low temperature) при постоянном значении напряжения $\sigma_{m}$ (maintaining); этап $3-$ полная разгрузка образца; этап 4 - последующее восстановление исходной формы при нагревании образца до температуры выше температуры стеклования $T_{r e c}$ (recovery temperature) (рис. 1).
Исследуемый образец КПК рассматривался в качестве ТМ-устройства, используемого в трансформируемых конструкциях космического назначения, поэтому наиболее подходящим режимом программирования являлся контроль $\sigma_{m}$. При использовании трехточечного изгибающего зажима в TMA максимальное значение прикладываемой силы к образцу КПК составило $1.2 \mathrm{~N}$ $\left(\sigma_{m} \approx 15 \mathrm{MPa}\right)$, при этом максимальное значение деформации $\varepsilon_{m} \approx 20 \%$. Для определения наиболее эффективной $T_{\text {prog }}$ с точки зрения восстановления формы нами были получены результаты исследования ТМ-цикла ЭПФ у КПК при $T_{p r o g}=55,65$ и $80^{\circ} \mathrm{C}$. При этом значение $T_{\text {rec }}$ должно быть на $20-30^{\circ} \mathrm{C}$ больше $T_{p r o g}$; $T_{\text {low }} \approx 23^{\circ} \mathrm{C}$. ТМ-исследования ЭПФ проводились без выдержки $\left(t_{H}=0\right)$ образца при установленном $\sigma_{m}$ и при выдерживании в течение $t_{H 1}=10 \mathrm{~min}$ в конце этапа $1 \mathrm{\text {в }}$ высокоэластическом состоянии и в течение $t_{H 2}=10 \mathrm{~min}$ в конце этапа 2 в застеклованном состоянии за один ТМ-цикл $\left(t_{H 12}=t_{H 1}+t_{H 2}=20 \mathrm{~min}\right)$. Значение температуры $T_{\mathrm{SW}}$ (switching temperature), при которой происходит критическое изменение формы образца при свободном восстановлении замороженной деформации, определялось как точка перегиба кривой восстановления (зависимость $\varepsilon(T)$ ) при нагревании от $T_{l o w}$ до $T_{r e c}$ на этапе 4 цикла ТМ-анализа ЭПФ.

Определяющим параметром ЭПФ является коэффициент восстановления формы $\left(R_{r}\right)$, показывающий долю обратимых деформаций, приобретенных в результате механического воздействия на образец в высокоэластическом состоянии:

$$
R_{r}=\frac{\varepsilon_{m}-\varepsilon_{p}}{\varepsilon_{m}} \cdot 100 \%,
$$

где $\varepsilon_{m}-$ значение общей деформации, определяемой как сумма мгновенной упругой $\varepsilon_{l}$ и запаздывающей высокоэластической деформации $\varepsilon_{c}\left(\varepsilon_{m}=\varepsilon_{l}+\varepsilon_{c}\right), \varepsilon_{p}-$ необратимая пластическая деформация. Наряду с $R_{r}$ важным параметром ЭПФ является коэффициент фиксации формы $\left(R_{f}\right)$, определяющий долю фиксированных деформаций, т.е. способность материала „запоминать“ временную форму:

$$
R_{f}=\frac{\varepsilon_{u}}{\varepsilon_{m}} \cdot 100 \%,
$$

где $\varepsilon_{u}$ - деформация, установившаяся в результате мгновенного восстановления некоторой части структурных единиц после снятия нагрузки $\varepsilon_{m}$ на этапе 3 .

ДМА-кривые $E^{*}$ (рис. 2) описывают вязкоупругое поведение образца КПК в интервале температур от 0 до $105^{\circ} \mathrm{C}$. На кривой 1 отчетливо выражена область снижения динамического модуля упругости $E^{\prime}$ с 26 до $2.7 \mathrm{GPa}$ в диапазоне от 20 до $90^{\circ} \mathrm{C}$, что соответствует переходу связующего композита из стеклообразного состояния в высокоэластическое. При использовании частоты нагружения $1 \mathrm{~Hz}$ происходит смещение значения максимума пика $\tan \delta$ в высокотемпературную область на $5-15^{\circ} \mathrm{C}$ [7]. Поэтому нами были определены 


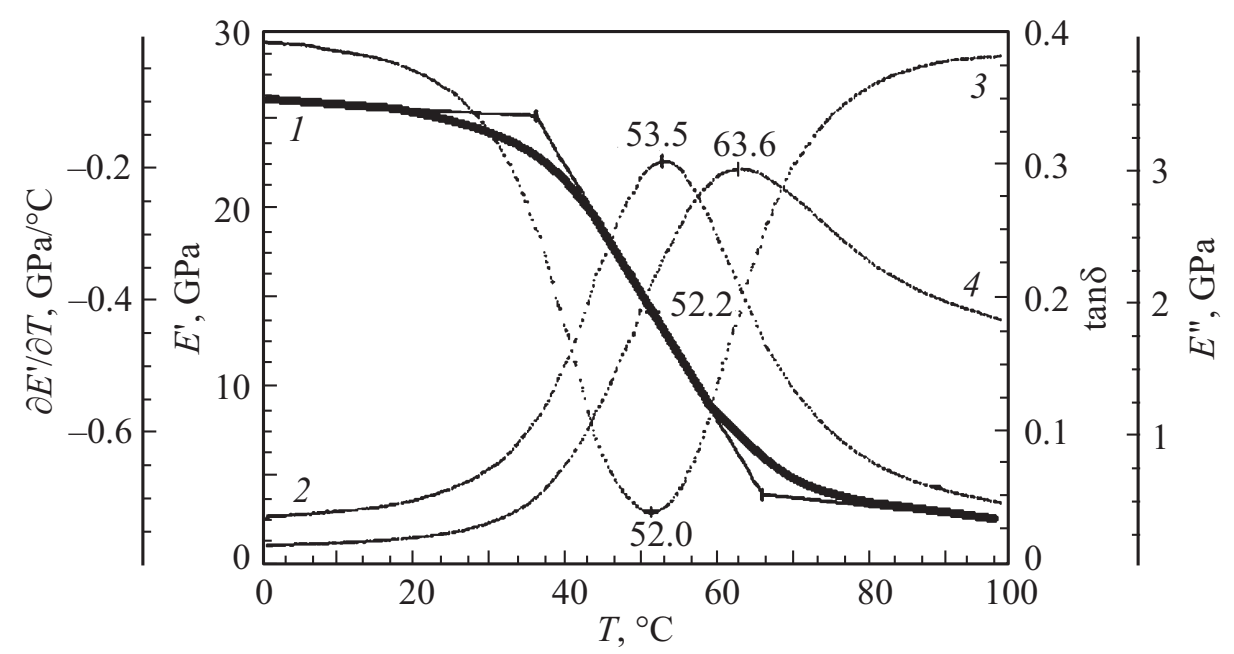

Рис. 2. Термомеханические кривые температурных зависимостей динамического модуля упругости $E^{\prime}(1)$, модуля механических потерь $E^{\prime \prime}(2)$, производной $E^{\prime}$ по температуре $\partial E^{\prime} / \partial T(3)$ и тангенса угла механических потерь $\tan \delta(4)$ для полиуретанового композита с памятью формы. Числа около кривых соответствуют температуре максимумов и минимумов сигналов.

величины $T_{g}$ для образцов КПК как значения точки перегиба на кривой $E^{\prime}(T)$, которые близки к значениям максимума пика $E^{\prime \prime}(T)$ и минимума пика $\partial E^{\prime} / \partial T(T)$ [8]. Исходный образец КПК имел значение $T_{g}=52.2^{\circ} \mathrm{C}$, что на $3^{\circ} \mathrm{C}$ ниже температуры стеклования неармированной полиуретановой матрицы.

На ТМ-кривой $\varepsilon(t)$ начиная с тринадцатой минуты $(t=13 \mathrm{~min})$ можно наблюдать запаздывающую высокоэластическую деформацию $\varepsilon_{c}$, описывающую релаксационную природу деформации ПМ (рис. 3, $a, b)$. Во время охлаждения молекулярные цепи, находящиеся все еще в высокоэластическом состоянии, испытывают под действием теплового движения беспорядочные толчки, приводящие к изменению конформационных состояний, при этом уменьшается значение $\varepsilon_{u}$, что в свою очередь ведет к уменьшению значения $R_{f}$. Выдерживание образца при постоянном $\sigma_{m}$ в застеклованном состоянии приводит к уменьшению доли мгновенной обратимой деформации, возникающей после разгрузки образца, при этом увеличивается значение $R_{f}$. Поэтому выдерживание образца в конце этапа 1 не является эффективным инструментом улучшения фиксации временной формы.

TMA-кривые $\varepsilon(T)$ показывают, что значение $T_{\mathrm{SW}}$ практически не зависит от величины $\sigma_{m}$ и $t_{H}$, однако сильно зависит от значения $T_{\text {prog }}$ (рис. $3, c, d$ ). Увеличение значения $T_{\text {prog }}$ на 10 и $25^{\circ} \mathrm{C}$ приводит к смещению значения $T_{\mathrm{SW}}$ в высокотемпературную область на 5 и $9^{\circ} \mathrm{C}$ соответственно. Также увеличение значения $T_{\text {prog }}$ ведет к расширению температурного интервала восстановления замороженной деформации в среднем на $15-20^{\circ} \mathrm{C}$.

Значения параметров $\varepsilon_{m}, \varepsilon_{p}$ и $\varepsilon_{u}$, необходимых для расчета $R_{f}$ и $R_{r}$ (см. таблицу), определялись при помощи ТМА-данных (рис. 3). Максимальное значение $R_{r}=99.98 \%$ было получено при температу-
Экспериментально полученные значения параметров эффекта памяти формы для конструкционного полиуретанового композита

\begin{tabular}{c|c|c|c|c|c}
\hline$T_{g},{ }^{\circ} \mathrm{C}$ & $E^{\prime}, \mathrm{GPa}$ & $T_{\text {prog }},{ }^{\circ} \mathrm{C}$ & $T_{\mathrm{SW}},{ }^{\circ} \mathrm{C}$ & $R_{r}, \%$ & $R_{f}, \%$ \\
\hline \multirow{3}{*}{$52.2 \pm 1$} & \multirow{4}{*}{26} & $55 \pm 1$ & 57.3 & 98 & 95.4 \\
& & $65 \pm 1$ & 62.4 & 99.9 & 97.8 \\
& & $80 \pm 1$ & 66.5 & 99.8 & 93.9 \\
& & \multicolumn{5}{|c}{$t_{H}=0 \mathrm{~min}$} \\
& & $55 \pm 1$ & 57.3 & $96(96.8)^{*}$ & 99.7 \\
& & $65 \pm 1$ & 62.2 & $96.9(97.2)^{*}$ & 99.3 \\
& & $80 \pm 1$ & 66.4 & $94.6(97.5)^{*}$ & 99.1
\end{tabular}

* Значения, полученные при $T_{r e c}>T_{p r o g}$ на $45^{\circ} \mathrm{C}$.

pe $T_{\text {prog }}=65^{\circ} \mathrm{C} \quad$ и $t_{H}=0 \mathrm{~min}, \quad$ а $\quad R_{f}=99.70 \%$ при $T_{\text {prog }}=55^{\circ} \mathrm{C}$ и $t_{H 12}=20 \mathrm{~min}$. Увеличение температуры $T_{\text {prog }}$ до $80^{\circ} \mathrm{C}$ приводит к снижению значений $R_{f}$ до $93.90 \%$ и $R_{r}$ до $94.60 \%$.

Ухудшение эффекта восстановления формы происходит из-за существенного перемещения молекулярных сегментов ПМ при деформировании. Это происходит вследствие ослабления межмолекулярных связей, которые до этого фиксировали их в определенном пространственном положении. Таким образом, если после деформирования образца произвести быстрое его охлаждение, снизив долю высокоэластической деформации, можно предотвратить существенную перестройку структурных единиц и тем самым повысить значение $R_{r}$. Если при этом произвести выдерживание материала при установленном постоянном значении $\sigma_{m}$ в застеклованном состоянии, то можно повысить и качество фиксации (упаковки) образца, оставляя высоким значение $R_{r}$ (развертывание). 

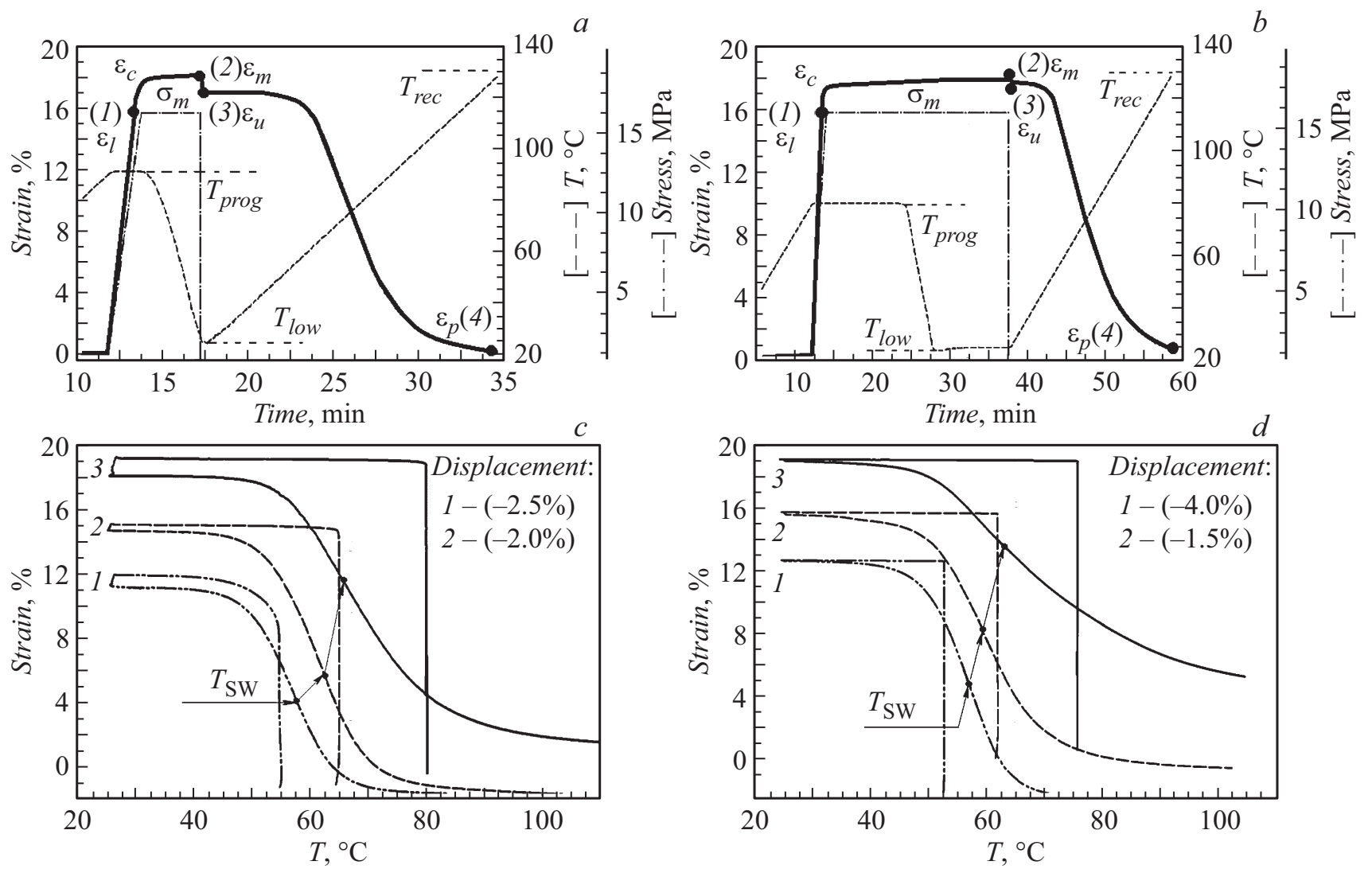

Рис. 3. Термомеханические кривые деформации, температуры и напряжения в зависимости от времени для полиуретанового композита с памятью формы, деформированного при $T_{p r o g}=80^{\circ} \mathrm{C}$ и $t_{H}=0(a), t_{H 12}=20$ min $(b)$, и температурные зависимости деформации при $t_{H}=0(c)$ и $t_{H 12}=20 \min (d) ; T_{\text {prog }},{ }^{\circ} \mathrm{C}: 1-55,2-65,3-80$.

В работе показана возможность использования трехточечного изгибающего зажима для термомеханического анализа эффекта памяти формы конструкционного полиуретанового композита, используемого для изготовления развертываемых конструкций космического назначения. Установлено, что максимальное значение $R_{r}(99.98 \%)$ образца КПК было получено в режиме контролируемой изгибающей нагрузки $(F=1.2 \mathrm{~N})$ при $T_{\text {prog }}=65^{\circ} \mathrm{C}$ и $t_{H}=0 \mathrm{~min}$. Показано, что выдерживание образца полиуретанового композита в застеклованном состоянии в течение $10 \mathrm{~min}$ при постоянной нагрузке позволяет увеличить $R_{f}$ до $99.70 \%$. Выявлено, что при увеличении значения температуры деформирования $T_{\text {prog }}$ на 10 и $25^{\circ} \mathrm{C}$ происходит смещение температуры критического изменения формы образца $\left(T_{\mathrm{SW}}\right)$ при свободном восстановлении замороженной деформации в высокотемпературную область на 5 и $9^{\circ} \mathrm{C}$ соответственно,

\section{Финансирование работы}

Работа выполнена при финансовой поддержке Правительства РФ (Министерства образования и науки РФ) по договору 02.G25.31.0147.

\section{Список литературы}

[1] Dao D.T., Ha N.S., Goo N.S., Yu W.-R. // J. Intell. Mater. Syst. Struct. 2017. V. 29. N 8. P. 1560-1574. DOI: $10.1177 / 1045389 X 17742728$

[2] Hager M.D., Bodea S., Weber C., Schubert U.S. // Prog. Polymer Sci. 2015. V. 49-50. P. 3-33. DOI: $10.1016 /$ j.progpolymsci.2015.04.002

[3] Huang W.M., Yang B., Zhao Y., Ding Z. // J. Mater. Chem. 2010. V. 20. N 17. P. 3367-3381. DOI: 10.1039/B922943D

[4] Титов М.А., Власов А.Ю., Пасечник К.А., Масалимов Р.Ф., Обверткин И.В. Трансформируемый рефлектор космических систем связи. Патент РФ 179275. Заявл. 21.12.2017. Опубл. 07.05.2018. Бюл. № 13.

[5] Applications Table. SMP Technologies Inc. URL: http://www2.smptechno.com/en/smp

[6] Tobushi H., Hayashi Sh., Kojima Sh. // JSME Int. J. 1992. V. 35. N 3. P. 296-302. DOI: 10.1299/jsmea1988.35.3_296

[7] Нильсен Л. Механические свойства полимеров и полимерных композиций / Пер. с англ. П.Г. Бабаевского. М.: Химия, 1978. $312 \mathrm{c}$.

[8] Стариев О.В., Каблов Е.Н., Махоньков А.Ю. // Вестн. МГТУ им. Н.Э. Баумана. Сер. Машиностроение. 2011. № SP2. C. 104-113. 